\title{
Structural Reliability Improvement Using In-Service Inspection for Intergranular Stress Corrosion of Large Stainless Steel Piping
}

\author{
A. Guedri, Y. Djebbar, Moe. Khaleel and A. Zeghloul \\ Additional information is available at the end of the chapter
}

http://dx.doi.org/10.5772/48521

\section{Introduction}

One of the important degradation mechanisms to be considered for alloyed steels, especially austenitic stainless steels, is stress corrosion cracking. This mechanism causes cracking in the material due to the combined action of corrosion and mechanical stresses. The purpose of this chapter is to apply probabilistic fracture mechanics (PFM) to the analysis of the influence of Remedial Actions on structural reliability. PFM provides a technique for estimating the probability of failure of a structure or component when failures are considered to occur as the result of the sub critical and catastrophic growth of an initial crack-like defect. Such techniques are inherently capable of treating the influence of nondestructive inspections. For these reasons, PFM is becoming of increased usefulness in analysis of the reliability of modem structures.

Various papers in the literature addressed the probabilistic failure analysis of components subjected to Stress Corrosion Cracking (SCC). Probabilistic failure analysis of nuclear piping of BWR plant was carried out by You and Wu (You Jang-Shyong, et al., 2002). Ting (Ting K, 1999) analyzed the crack growth due to Intergranular Stress Corrosion Cracking (IGSCC) in stainless steel piping of BWR plants. Zhang et al. (Zhang S et al., 2002) carried out experimental investigations to determine the time to crack initiation and crack propagation velocity for IGSCC in sensitized type AISI304 stainless steel in dilute sulphate solutions. From the statistical analysis results obtained by Zhang et al. (Zhang S et al., 2002), it was seen that the time of crack initiation follows an exponential distribution, where as the crack growth rate follows a Weibull distribution. Harris et al. (Harris et al., 1992) developed a computer code named PRAISE (piping reliability analysis, including seismic events) for estimating the probability of pipe leak age under SCC. Rahman (Rahman S. 1997) has 
developed another computer code named PSQUIRT (probabilistic see page quantification of upsets in reactor tubes) to determine the probability of leak age of piping made of stainless steel and carbon steel subjected to intergranular stress corrosion cracking (IGSCC) and corrosion fatigue. Failure probabilities of a piping component subjected to SCC was computed in (Priya C et al., 2005 and Guedri et al., 2009a , 2009b) using a Monte Carlo simulation (MCS) technique.

In this chapter, a piping component made of AISI 304 stainless steel is considered for the analysis, because this type of steel is highly susceptible to SCC. Empirical relations are used to model the initiation and early growth rate of cracks. Fracture mechanics concepts are used deterministically in this study. Although the general methodology recommended in the computer program Piping Reliability Analysis Including Seismic Events (pc-PRAISE) (Harris et al., 1996) is used for the modeling of initiation and propagation of cracks, the American Society of Materials (ASM) recommendations (American Society of Materials, 1996) are used for computing the stress intensity factors. The microstructural properties of the material and operating conditions like pressure and temperature show variations during the lifetime of the pipe. In order to account for these variations, degree of sensitization, applied stress, initiation time of cracks, crack growth velocity after initiation, and initial crack length are considered as random variables.

The present calculations build on past studies by the nuclear power industry: General Electric Company (GEC) (General Electric Company, 1982a, 1982b) and Nuclear Regulatory Commission (NRC) (Hazelton, 1988), which have addressed both Inter-Granular StressCorrosion Cracking (IGSCC) causes and preventive actions. A critical issue has been the difficulty of using Ultrasonic Testing (UT) to detect IGSCC. Pacific Northwest National Laboratory (PNNL) past research on Non-Destructive Examination (NDE) reliability has included systematic studies to quantify NDE effectiveness. The first statistically based data for the Probability of Detection (POD) of IGSCC in weld of stainless steel piping were generated based on a piping inspection round robin (Doctor et al., 1983). The resulting POD data related to crack size and other important variables covered the performance of several inspection teams participating in the round robin. The first part of this chapter describes the stress-corrosion cracking model used in the pc-PRAISE (Harris et al., 1981, 1986a, 1986b) for simulating the initiation and growth of IGSCC cracks. This model is based on laboratory data from IGSCC tests in combination with calibration of the model using field data from pipe-cracking experience. PNNL has improved on the prior calibrations (Harris et al., 1986b) by making adjustments to the modeling of plant loading/unloading cycles in addition to adjustments to residual stress levels. The crack detection data (POD curves) by use of the pcPRAISE model are also described. A parametric approach was adopted in the present calculations to characterize IGSCC by a single damage parameter $\left(D_{\text {sigma }}\right)$. This parameter depends on residual stresses, environment conditions, and degree of sensitization. In the second part, a matrix of calculations to address an example of large pipe size, materials, and service conditions was developed. The results of these calculations quantify the reductions in failure probabilities that can be achieved with various In-Service Inspection (ISI) strategies. The final subpart of this chapter presents conclusions regarding ISI effectiveness as a mitigation action to enhance the reliability of Boiler Water Reactor piping. 


\section{Methodology}

\subsection{Overview of the PRAISE code}

The present section describes probabilistic fracture mechanics calculations that were performed for selected components using the PRAISE computer code. The calculations address the failure mechanisms of stress corrosion cracking and intergranular stress corrosion cracking for components and operating conditions that are known to make particular components susceptible to cracking. Comparisons with field experience showed that the PRAISE code predict relatively high failure probabilities for components under operating conditions that have resulted in field failures. It was found that modeling assumptions and inputs tended to give higher calculated failure probabilities than those derived from data on field failures. Sensitivity calculations were performed to show that uncertainties in the probabilistic calculations were sufficiently large to explain the differences between predicted failure probabilities and field experience.

The first version of PRAISE (Harris et al., 1981) was developed in the 1980s by Lawrence Livermore National Laboratory under contract to NRC, with the initial application to address seismic-induced failures of large-diameter reactor coolant piping. This version of the code addressed failures (small leaks and ruptures) associated with fabrication flaws in welds that were allowed to grow as fatigue cracks until they either caused the pipe to leak or exceed a critical size needed to result in unstable crack growth and pipe rupture. The next major enhancement to the code (Harris et al., 1986b) addressed IGSCC and simulated both crack initiation and crack growth. The enhanced code allowed for crack initiation at multiple sites around the circumference of a girth weld and simulated linking adjacent cracks to form longer cracks more likely to cause larger leaks and pipe ruptures. In the early 1990s a version of PRAISE (pc-PRAISE) was developed to run on personal computers (Harris and Dedhia, 1992). The mid-1990s saw the development of methods for risk-informed in-service inspection, for which there were many new applications of PRAISE. A new commercial version of PRAISE (win PRAISE) was made available by Dr. David Harris of Engineering Mechanics Technology that simplified the input to the code with an interactive front end (Harris and Dedhia, 1998). During this same time period, PNNL made numerous applications of PRAISE to apply probabilistic fracture mechanics to support the development of improved approaches to in-service inspection (Khaleel and Simonen, 1994a; 1994b; 2000; Khaleel et al., 1995; Simonen et al., 1998; Simonen and Khaleel, 1998a; 1998b). The objective of this work was to ensure that changes to inspection requirements could be justified in terms of reduced failure probabilities for inspected components. Other work at PNNL for NRC (Khaleel et al., 2000) involved evaluations of fatigue critical components that could potentially attain calculated fatigue usage factors in excess of design limits (usage factors greater than unity).The most recent upgrades to PRAISE (Khaleel et al., 2000) were developed to support these fatigue evaluations, with the upgrade consisting of a model similar to that for IGSCC but directed at predicting the probabilities of initiating fatigue cracks. This new model was used to develop the technical 
basis for changes to Appendix L of American Society of Mechanical Engineers (ASME) Section XI that addresses fatigue critical locations in pressure boundary components (Gosselin et al., 2005). The PRAISE code has been extensively documented, successfully applied to a range of structural integrity issues, and has been available since the 1980s as a public domain computer code. However, the code has not been maintained and upgraded in an ongoing manner. Upgrades have been performed to meet the needs of immediate applications of the code and as such have served to fill very specific gaps in capabilities of PRAISE.

Other probabilistic fracture mechanics codes for piping have been developed to calculate failure probabilities for piping. The SRRA code (Bishop 1997; Westinghouse Owners Group, 1997) developed by Westinghouse follows much the same approach as the PRAISE code, but is limited to failures associated with cyclic fatigue stresses considers only preexisting fabrication flaws. Fatigue crack initiation has been approximated by assuming a very small initial crack, but with only one initiation site per weld. Stress corrosion cracking is similarly treated by postulating a very small initial crack, and growing the crack according to user-specified parameters for a crack growth equation. The SRRA code includes an importance sampling procedure that gives reduced computation times compared to the Monte Carlo approaches used by PRAISE. Also the model can simulate uncertainties in a wide range of parameters such as the applied stresses. The European NURBIM (Brickstad et al., 2004) has looked at a number of codes including PRAISE as part of an international benchmarking study. Included were a Swedish code NURBIT (Brickstad and Zang, 2001), the PRODIGAL code from the United Kingdom (Bell and Chapman, 2003), a code developed in Germany by GRS (Schimpfke, 2003), a Swedish code ProSACC (Dillstrom, 2003) and another code (STRUEL) from the United Kingdom (Mohammed, 2003).

This review concluded that none of the other benchmarked codes provided capabilities significantly different than or superior to the capabilities of PRAISE. In any case, the predictions of all such codes are limited in large measure by the quality of the values that can be established for the input parameters, as well as the validation with service experience.

\subsection{Stress corrosion cracking model}

SCC is a corrosion mechanism that forms cracks in susceptible material in the presence of an aggressive environment and tensile stresses. SCC can be intergranular or transgranular in nature depending on the material, level of stress, and environment (ASME, 1998). Austenitic stainless steels are commonly used in power generating industries because of high ductility and fracture toughness (American Society of Materials, 1996).This type of steel is used in applications where corrosion resistance is an important characteristic.

The methodology recommended in pc-PRAISE for modeling IGSCC in pipe is followed in this study. PRAISE model the occurrence of IGSCC by considering it as a two-stage process, namely, (1) crack initiation and (2) crack propagation. 


\subsubsection{Crack initiation model}

\subsubsection{Time to initiation}

Time to initiation of stress corrosion crack is considered as a function of damage parameter, $D_{\text {sigma, }}$ which represent effects of loading, environment and material variables on IGSCC. The damage parameter is given by

$$
D_{\text {sigma }}=f_{1}(\text { material }) \times f_{2}(\text { environment }) \times f_{3}(\text { looding })
$$

where $f_{1}, f_{2}$ and $f_{3}$ are given by

$$
f_{1}=C_{1}(P a)^{C_{2}}
$$

where $\mathrm{Pa}$ is a measure of degree of sensitization, given by Electrochemical Potentiokinetic

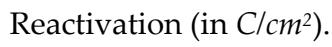

$$
f_{2}=O_{2}^{C_{3}} \exp \left[C_{4} /(T+273)\right] \log \left(C_{5} \gamma^{C_{6}}\right)
$$

where $\mathrm{O}_{2}$ is oxygen concentration in ppm, $T$ is temperature in degrees centigrade, and $\gamma$ is water conductivity in $\mu \mathrm{s} / \mathrm{cm}$. The loading term $f_{3}$ is considered to be a function of stress. For constant applied load case, $f_{3}$ is given by

$$
f_{3}=\left(C_{8} \sigma^{C_{9}}\right)^{C_{7}}
$$

where $\sigma$ is stress in $M P a . C_{1}$ to $C_{9}$ are constants whose values depend on type of material. Values for these constants are presented in Table1.

\begin{tabular}{lccccccccc}
\hline Constant & $C 1$ & $C 2$ & $C 3$ & $C 4$ & $C 5$ & $C 6$ & $C 7$ & $C 8$ & $C 9$ \\
\hline Value & 23.0 & 0.51 & 0.18 & -1123.0 & 8.7096 & 0.35 & 0.55 & $2.21 \times 10^{-15}$ & 6.0 \\
\hline
\end{tabular}

Table 1. Numerical values of constants $C_{i}$ used for predicting the initiation and propagation of SCC for AISI304 (Harris et al., 1992).

The time to initiation $t_{I}$ for a given $D_{\text {sigma }}$ is considered as a random variable following lognormal distribution. The mean and standard deviation of $\log \left(t_{I}\right)$ are given by:

Mean value of

$$
\log \left(t_{I}\right)=-3.10-4.21 \log \left(D_{\text {sigma }}\right)
$$

Standard deviation of

$$
\log \left(t_{I}\right)=0.3081
$$




\subsubsection{Crack size at initiation}

In pc-PRAISE, shape of surface crack initiated due to IGSCC is considered to be semielliptical (Fig.1), which is also consistent with shapes of stress corrosion cracks reported by Helie (Helie M, et al., 1996) and by Lu (Lu B T et al., 2005). Surface length of initiated cracks, $(l=2 b)$, is assumed to be log normally distributed with a median value of $3.175 \mathrm{~mm}$ and a shape parameter of 0.85 (Harris et al., 1996). Depth of initiated crack is taken to be $0.0254 \mathrm{~mm}$.

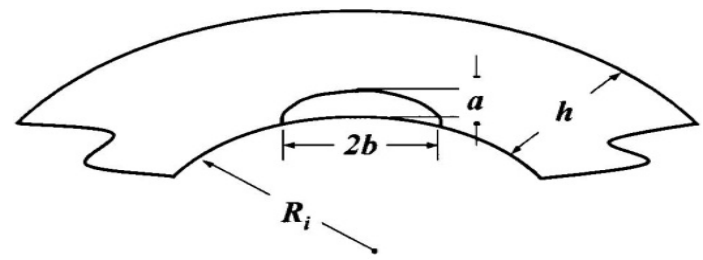

Figure 1. Geometry of the part-through circumferential crack considered

\subsubsection{Crack growth model}

The growth of very small cracks that have just initiated cannot be treated from a fracture mechanics standpoint (Andresen PL, 1994). Therefore, an initiation velocity is assigned to newly initiated cracks

$$
\log \left(v_{1}\right)=J+G \log \left(D_{\text {sigma }}\right)
$$

where $J$ is normally distributed and $G$ is a constant.

It can be noted that equation (6) is similar in form (power law) as that proposed by Helie (Helie M, et al., 1996), based on experimental observations. For AISI 304 austenitic stainless steel, $J$ has a mean of 2.551 and standard deviation of 0.4269 , and $G=1.3447$ (Harris et al., 1996). From parametric studies carried out, a value of $5 \%$ coefficient of variation of $\log \left(v_{1}\right)$ was found to be critical to life of piping component (Priya $C$ et al., 2005), and hence this value is used in this study.

The procedure followed for transition from initiation to fracture mechanics crack growth rate in the present study is (Harris et al., 1996):

- Pre-existing cracks always grow at fracture mechanics velocity.

- Initiation velocity is always assigned to initiate cracks.

- At any given time, if fracture mechanics velocity $\left(v_{2}\right)$ is greater than initiation velocity (i.e. $v_{2}>v_{1}$ ) and depth of crack is greater than $2.54 \mathrm{~mm}$, that particular crack grows at fracture mechanics velocity thereafter.

- If the stress intensity factor for a crack is negative, the crack will not grow.

Fracture mechanics based crack growth velocity, v2 (inches/year), is given by Harris (Harris et al., 1996): 


$$
\log \left(v_{2}\right)=C_{14}+C_{15} D_{K}
$$

where $D_{K}$ is the damage parameter given by

$$
D_{K}=C_{12} \log \left[f_{2}(\text { environment })\right]+C_{13} K
$$

where $K$ is stress intensity factor, $C_{12}, C_{13}$ and $C_{15}$ are constants and $C_{14}$ is normally distributed.

For AISI 304 austenitic stainless steel, $C_{12}=0.8192, C_{13}=0.03621$ and $C_{15}=1.7935$; mean value of $C_{14}=-3.1671$ and standard deviation of $C_{14}=0.7260$ (Harris et al., 1992).

From a probabilistic failure analysis of austenitic nuclear pipe against SCC, Priya in (Priya C et al., 2005) inferred that expressions given in PRAISE for computation of stress intensity factors for modeling crack propagation need modification. This modification has been introduced by using well-accepted expressions given in ASM Handbook (American Society of Materials, 1996), and with modified PRAISE approach, stochastic propagation of stress corrosion cracks with time has been studied. The expression for the stress intensity factor for a part-through crack in a hollow cylinder is given by

$$
K=S F \sqrt{(\pi a)}
$$

where $S$ is the tensile or bending stress (assumed to be the value of applied stress in the study), $\mathrm{F}$ is a function of $a / b, R / h$, and $a / h$, where a is the crack depth, $b$ is half the crack length, $R$ is the inner radius of the cylinder, and $h$ is the wall thickness. The values of $F$ are calculated for length and depth directions separately using the tables given in ASM Handbook (American Society of Materials, 1996). Since these factors are applicable for values of $a / b$ less than 1.0, the expression for stress intensity factor for part-through cracks in a finite plate is used when $a / b$ becomes greater than 1.0. This expression is given by

$$
K=\sigma F_{s} \sqrt{\left(\frac{\pi a}{Q}\right)}
$$

where $\sqrt{Q}$ is the crack shape parameter which depends on $a / b$ ratio and $F_{s}$ is a function of $a / b, a / h$, and $b / W$ and $\varphi$ such that

$$
F_{s}=\left[M_{1}+M_{2}\left(\frac{a}{h}\right)^{2}+M_{3}\left(\frac{a}{h}\right)^{4}\right] G_{1} f_{\varphi} f_{w}
$$

where

$$
M_{1}=\left[1.0+0.04\left(\frac{b}{a}\right)\right]\left(\frac{b}{a}\right)^{1 / 2}
$$




$$
\begin{gathered}
M_{2}=0.2\left(\frac{b}{a}\right)^{4} \\
M_{3}=-0.11\left(\frac{b}{a}\right)^{4} \\
G_{1}=1+\left[0.1+0.35\left(\frac{b}{a}\right)\left(\frac{a}{h}\right)^{2}\right](1-\sin \varphi)^{2} \\
f_{\varphi}=\left[\left(\frac{b}{a}\right)^{2} \cdot \sin ^{2} \varphi+\cos ^{2} \varphi\right. \\
f_{w}=\sqrt{\sec \left[\left(\frac{\pi b}{W}\right) \sqrt{\left(\frac{a}{h}\right)}\right.}
\end{gathered}
$$

$\varphi$ is the parametric angle measured from the plate surface toward the centre of the crack (i.e. $\varphi=0^{\circ}$ is on the plate surface and $\varphi=90^{\circ}$ is at the maximum depth of the crack) and $W$ is the width of the plate (assumed to be $50 \mathrm{~mm}$ in the study). When the crack grows to become a through-wall crack, the expression for stress intensity factor used is

$$
K=S F \sqrt{(\pi b)}
$$

Here, $F$ is given by the expression

$$
F=A_{1}+A_{2} \alpha+A_{3} \alpha^{2}+A_{4} \alpha^{3}+A_{5} \alpha^{4}+A_{6} \alpha^{5}+A_{7} \alpha^{6}
$$

where $\alpha$ is one-half of the angle that represents the crack tip-to-tip circumferential arc and the coefficients $A_{1}$ to $A_{6}$ are computed from the table given in ASM Handbook .

It has been noted that trend of distribution of crack depths at initial stages is in satisfactory agreement with relevant experimental observations reported in literature.

\subsection{Multiple cracks}

In materials subjected to IGSCC, many cracks would initiate successively and propagate simultaneously, and hence multiple cracks can be present in a given weld. The expressions, given in PRAISE, for determining statistical properties of $t_{t}$ are mainly based on data from laboratory experiments on specimens about $50 \mathrm{~mm}$ long. Hence, these expressions are applicable to specimens of about $50 \mathrm{~mm}$ only. This is taken into account in PRAISE, by considering a given weld in the pipe to be composed of $50 \mathrm{~mm}$ segments adding up to length of weld. Initiation time for each segment is assumed to be independent and identically distributed. 


\subsection{Coalescence of crack}

The multiple cracks that may be present can coalesce as they grow. Linkage of two cracks takes place if spacing between them is less than the sum of their depths. After coalescence of two cracks, the dimensions of modified crack are given by Eqn. (20).

$$
\text { Length, } l=l_{1}+d+l_{2} \text { and Depth, } a=a_{1} \text { or } a_{2} \text {, which is greater }
$$

where $l_{1}$ and $l_{2}$ are lengths of two cracks under consideration, $a_{1}$ and a2 are crack depths and $d$ is spacing between them.

The operating conditions and environmental conditions show variations during the lifetime of the power plant (Anoop M B et al., 2008). Also, there will be variations in micro-structural properties of the material of piping component. These variations should be taken into account while assessing the safety of the piping component against SCC. Various researchers have carried out studies on failure analysis against SCC in different types of components of power plants by considering different basic variables (such as those associated with material properties and applied loading) as random, (Harris et al., 1996; Ting K., 1999; Herrera ML et al., 1999; You J-S,2002; Priya C et al., 2005). However, safety assessment of nuclear power plant pipelines also involves information from expert judgment and/or data from in-service inspections.

\subsection{Residual stresses}

Residual stresses influence both crack initiation and propagation. The damage parameter $D_{\text {sigma }}$ is a function of the stress, which consists of both the applied (serviceinduced pressure and thermal) and residual stresses. The crack-tip stress-intensity factor is given by

$$
K=K_{a p}+K_{r e s}
$$

where $K_{a p}$ and $K_{\text {res }}$ are the stress-intensity factors attributable to the applied stress and residual stresses, respectively.

The calculations reported here are concerned with the stress corrosion cracking behavior of large pipes (Outside Diameter $>508 \mathrm{~mm}$ ). Residual stress is treated as a random variable in the Monte Carlo Simulation (MCS). Distributions of residual stress as a function of distance from the inner pipe wall were developed from experimental data for three categories of nominal pipe diameter. For large lines, residual stresses took the form of a damped cosine through the wall as based on data collected by GEC and Argon National Laboratory. Harris and Dedhia (Harris et al., 1996) documents the default pc-PRAISE inputs in detail for the complex pattern of residual stresses in large pipes. In summary, the inner surface had a mean tensile stress of $262 \mathrm{MPa}$. The through-thickness variation in stress had compressive stresses developing within the inner quarter-wall thickness and changing again to tension stress at greater depths. 


\subsection{Failure criteria}

The part-through initial stress corrosion cracks considered can grow and become unstable part-through cracks or stable or unstable through-wall cracks. The stability of the partthrough or through-wall crack is checked by comparing net-section stress with the flow stress of the material. The net-section stress criterion is applicable to very tough material, and the failure is due to the insufficient remaining area to support the applied loads (i.e. netsection stress due to applied loads becomes greater than the flow stress of the material). For leakage failure, the criterion was that of a crack depth equal to the pipe-wall thickness.

\subsection{Numerical simulation}

In this study, the stochastic evolution of cracks due to IGSCC in AISI304 austenitic stainless steel is simulated using MCS technique. The details regarding the random variables considered in this study are given in Table 2. $N$ values of $f_{1}$ and $f_{3}$ are computed using the $N$ values of $\mathrm{Pa}$ and generated using MCS. Using the values of $f_{1}, f_{2}$ (considered as deterministic), and $f_{3}, N$ values of damage parameter are obtained. This represents $N$ pipes with different damage parameters, which take into account the variation in microstructural properties of the material and the operating conditions. In order to take into account the variations in the time to initiation of stress corrosion cracks, the number of samples considered is $10 \mathrm{~N}$. For each sample, $n$ (the number of possible initiation sites in the pipe considering the weld length is divided into $25.4 \mathrm{~mm}$ long segments along the circumference of the pipe) values of $t_{l}$ are generated using MCS. In every time step, each one of the cracks is checked for initiation, values of initial crack depth and length are assigned to the initiated cracks and crack growth velocities are calculated. For all the initiated cracks in the $10^{5}$ samples generated, crack propagation velocities are calculated based on initiation and fracture mechanics considerations as is appropriate. After each time step, the failure criterion, in section 2.6 is checked. Failure probability $P_{f}$ is calculated as

$$
P_{f}=\frac{N_{f}}{N}
$$

where $N_{f}$ is the number of failure cases and $N$ is the total number of simulations.

Computer programs have been developed implementing the step-by-step procedure, in the form of flow charts, for computing failure probabilities using the net-section stress as failure criteria.

\section{Calibration of model}

The original calibration of the PRAISE model in (Harris DO et al., 1985) was redone by Khaleel et al. in (Khaleel MA. et al., 1995). The original calculations predicted substantial levels of material damage from loading and unloading events (i.e., complete start-up and shut-down of the plant) that used a model that applied strain-to-failure data from constant extension rate tests. A review of the damage model concluded that these predictions were 
extremely conservative and were inconsistent with more recent insights into stress corrosion cracking mechanisms. In the revised calculations, the loading/unloading events were decreased from once per year to once per 40 years, which essentially removed the contribution of these events to the calculated failure probabilities.

\begin{tabular}{ll}
\hline Outside diameter, $(\mathrm{mm})$ & 549 \\
\hline Wall thickness, $(\mathrm{mm})$ & 26.4 \\
\hline Welding residual stress, $(\mathrm{MPa})$ & $\begin{array}{l}\text { Randomized pc-PRAISE input values for } \\
\text { large lines with adjustment of: } \mathrm{f}=0.75 \\
\text { Stress at ID: Mean }=262\end{array}$ \\
\hline Axial component of primary stress, $(\mathrm{MPa})$ & 4 to 86 \\
\hline Flow stress of piping material, $(\mathrm{MPa})$ & Normal distribution \\
& Mean = 276 and Standard deviation= 29 \\
\hline Initial flaw distribution & Lognormal distribution \\
& Deterministic flaw depth=0.025 \\
& Mean flaw length=3.2 \\
& Shape parameter=0.85 \\
\hline POD Curves & Three POD Curves as per table3 \\
\hline Frequency of inspection, $(\mathrm{yr})$, & $5 / 10,4 / 4,1 / 1$ \\
(Time of initial ISI/ Frequency) & \\
\hline Range of $D_{\text {sigma }}$ parameter & 0.001 to 0.02 \\
\hline Crack initiation and growth & As per Eqs.1 to 10 \\
\hline
\end{tabular}

Table 2. Input values for parametric calculation including the effects of in-service inspection

Fig. 2 compares the original PRAISE cumulative leak probabilities (Harris DO et al., 1985) and results obtained by Khaleel in (Khaleel MA. et al., 1995), for various values of residual stress adjustment factors and plant loading/unloading frequencies. In this case, the adjusted residual stress level used to limit the disagreement between predicted and observed leak probabilities was set at $75 \%$ of their original values. The resulting predictions had a much more rational basis and were in very good agreement with operational data for time periods beyond 6 years. The less satisfactory level of agreement for time periods less than 6 years can be attributed in a large measure to lack of observed failure events for the early periods of plant operation.

\section{In-service inspection model}

Performance demonstrations have addressed two measures of NDE reliability-Probability of Detection (POD) and flaw sizing accuracy. Both measures impact the ability of an inspection program to enhance the reliability of piping. The detection of growing flaws with a high level of reliability is an important step to ensure that in-service inspections will reduce the failure probabilities of the piping locations being inspected. However, such inspections impact piping reliability only if the detected flaws are correctly sized such that needed repairs or other corrective actions are performed. Significant under sizing of flaws can result 
in incorrect conclusions. Flaws can be incorrectly classified as benign if their measured sizes are less than the sizes of the governing flaw acceptance criteria used to dictate repair decisions.

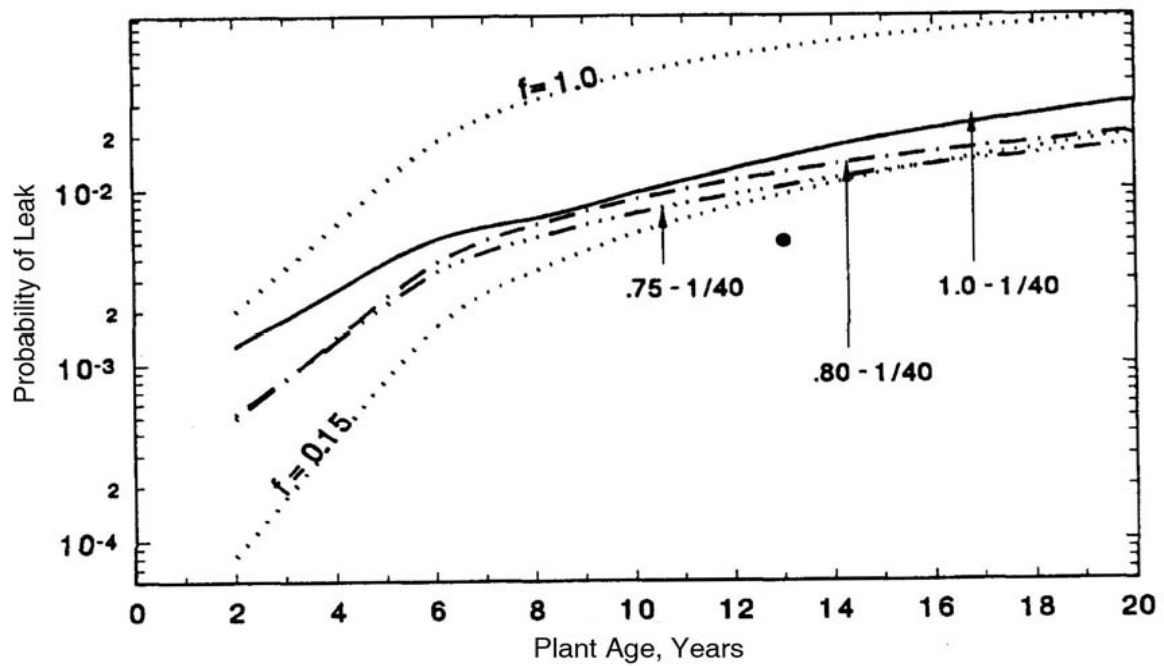

Figure 2. Field Observations of Leak Probabilities Compared with pc-PRAISE Results for Various Values of the Residual Stress Adjustment Factors and Plant Cycles (Large Diameter Pipes) (Khaleel MA. et al., 1995)

The procedures shown in Fig. 3 are applicable to a given location in a structure. The crack size distribution is combined with the non-detection probability to provide the postinspection distribution. The manner in which the cracks that escape detection grow is then calculated by fracture mechanics techniques. The cumulative probability of failure at any time is simply the probability of having a crack at that time equal to or larger than the critical crack size. The crack size distribution at the time of the first ISI can be calculated. This pre-inspection distribution is combined with the non-detection probability to provide the post-inspection distribution. Fracture mechanics calculations then proceed up to the next ISI, at which time the procedures are again applied. Calculations of the failure probability for the general model are performed numerically because of the complexity of the fracture mechanics calculations of the growth of two-dimensional cracks as well as the complicated bivariate nature of the crack size distribution.

\subsection{One-dimensional model}

Consideration of one-dimensional cracks greatly simplifies the probabilistic fracture mechanics model. The two-dimensional surface of the initial crack size shown in Fig. 1 becomes a line that is a function of only one length, which will be taken to be crack depth $a$. Additionally, the fracture mechanics calculations are considerably simplified, because only one dimension of crack growth has to be considered. However, if one-dimensional cracks in 
finite bodies are considered, numerical calculations of subcritical crack growth are often still necessary. The procedures involved for one-dimensional cracks are depicted in Fig. 5. For simplicity, only the case of a pre-service inspection is shown in Fig. 5, and the critical crack depth, $a_{c}$ is considered to be a constant.

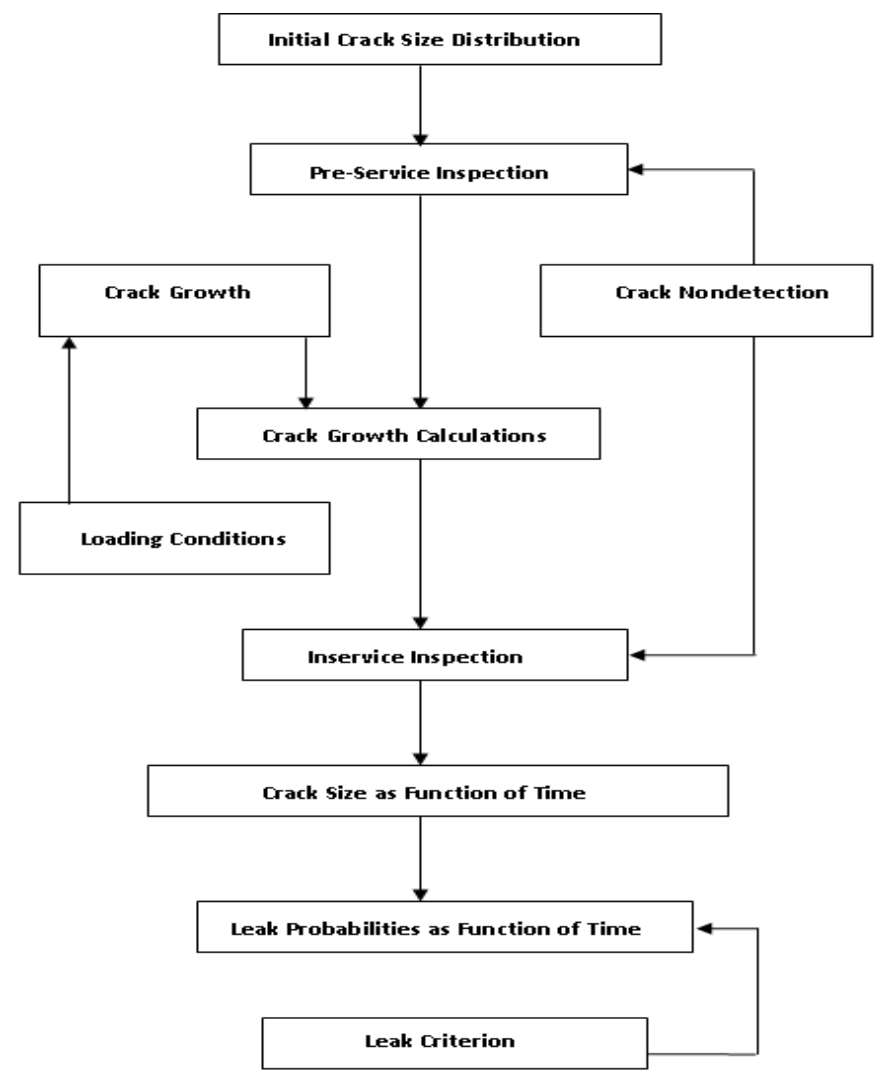

Figure 3. Computational procedure used in estimating leak probability for nuclear power plant piping

Let $P_{0}(a)$ be the probability density function of as-fabricated crack depth given that a crack is present. The as-fabricated complementary cumulative crack depth distribution is then given by

$$
P_{0}(a>x)=\int_{x}^{h} P_{0}(y) d y
$$

The density function and complementary cumulative distribution of crack depths following an inspection with nondetection probability $P_{N D}(a)$ are then given by

$$
P_{0}^{\prime}(a)=P_{0}(a) P_{\mathrm{ND}}(a)
$$




$$
P_{0}^{\prime}(a>x)=\int_{x}^{h} P_{0}^{\prime}(y) d y=\int_{x}^{h} P_{0}(y) P_{N D}(y) d y
$$
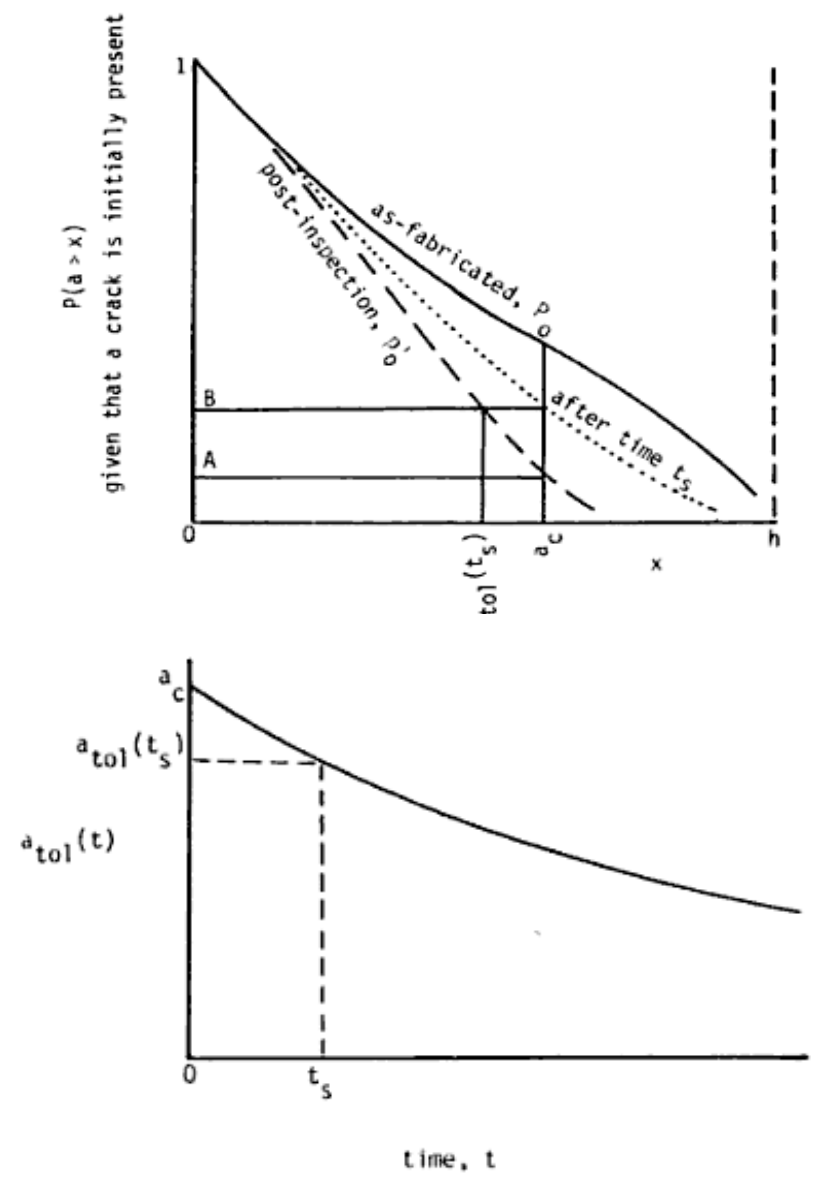

Figure 4. Procedures involved in calculating failure probability for one-dimensional crack problems (Harris DO et al., 1983).

The probability of failure at short time following the pre-service inspection is simply the probability of having a crack of depth greater than the critical value, $a_{c}$. Hence, for $t \sim 0$, the Point $A$ in Fig. 4 gives the cumulative failure probability (given that a crack is initially present).

During succeeding time, the cracks that are initially present can grow due to subcritical crack growth, such as fatigue or stress corrosion cracking. Fracture mechanics calculations 
could be performed to determine the entire crack size distribution as a function of time, such as shown by the dotted line in Fig.4. The cumulative failure probability at or before $t_{s}$ is then given by Point $B$ in Fig. 4. Such a procedure requires extensive fracture mechanics calculations of crack growth in order to accurately define the crack size distribution at various times. An alternative procedure is to define $a_{t o l}(t)$ to be the size of a crack at $t=0$ (initially) that will just grow to $a_{c}$ in time $t$ (Fig. 4) schematically shows $a_{t o l}(t)$. The probability of failure at or before $t$ is then simply the probability of initially having a crack bigger than $a_{t o l}(t)$. That is

$$
P_{0}^{\prime}(a>x)=\int_{a_{\text {tol }}(t)}^{h} P_{0}(y) P_{N D}(y) d y
$$

Hence, once $a_{t o l}(t)$ is known, the cumulative (conditional) failure probability is calculated in a straightforward manner. The failure rate, or hazard function, is equal to $(d P / d t) /(1-P)$. In the case where $P\left(t_{f}<t\right) \ll 1$, the $(1-P)$ term is nearly unity, and the failure rate is approximately given by the following

$$
\begin{gathered}
P\left(t_{f}<t\right)=\int_{a_{t o l}(t)}^{h} P_{0}(y) \cdot P_{N D}(y) d y \\
P_{f}(t)=\frac{d}{d t}\left[P\left(t_{f}<t\right)\right]=-\frac{d a_{t o l}(t)}{d t} P_{0}\left(a_{t o l}\right) P_{N D}\left(a_{t o l}\right)
\end{gathered}
$$

Consideration of the failure rate in conjunction with the tolerable crack depth simplifies analysis of the influence of ISI. The procedures for calculating the failure rate for an arbitrary schedule of in-service inspections are straightforward but lengthy. Details are provided in (Harris DO et al., 1983). The end result of the analysis is the following expression

$$
\frac{P_{f}(t) \text { with inspection }}{P_{f}(t) \text { without inspection }}=\prod_{n=0}^{k} P_{N D}\left[a_{n}(t)\right]
$$

The crack depth, $a_{n}(t)$, is shown schematically in Fig. 5 and is determined from fracture mechanics calculations. If $a_{t o l}(t)$ is the depth of an initial crack that would just grow to $a_{c}$ in time $t$, then $a_{n}$, is the depth this crack would have had at the arbitrary inspection times $t_{n}$.

The result expressed as Eqn. (29) shows that the relative benefit of ISI, when expressed as the ratio of failure rates with and without inspection, is independent of the initial crack size distribution. This ratio is dependent only on the nondetection probabilities and crack growth characteristics. The initial crack size distribution is currently ill-defined, and is a source of considerable uncertainty in probabilistic fracture mechanics analysis.

Another ill-defined parameter is the probability of initially having a crack in a body of volume $V$. This parameter is denoted as $p^{*}$. All failure probabilities just discussed were conditional on having an initial crack. To account for the possibility of not having a crack 
(that is, to make the results not conditional on having a crack to begin with) all those results are to be multiplied by $p^{*}$. This parameter is also not well defined, but cancels out in the relative benefit of ISI as expressed by Eqn. (29), because it appears in both the numerator and denominator.

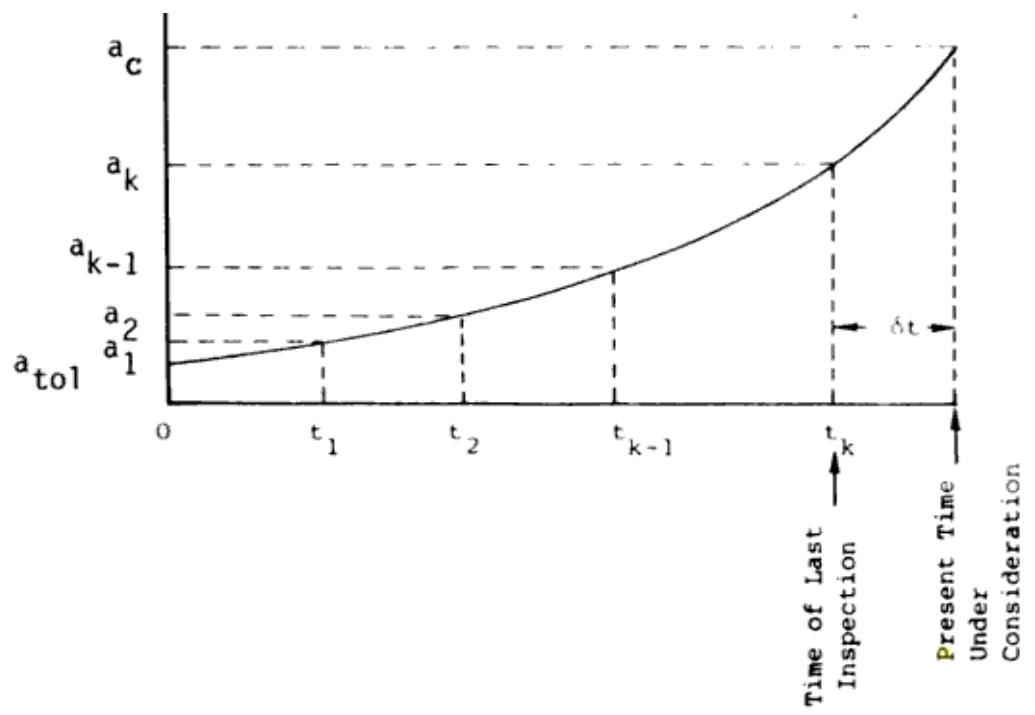

Figure 5. Schematic representation of $a$ from known subcritical crack growth results and specified inspection (Harris DO et al., 1983).

Thus, the relative benefit of ISI is independent of both the conditional initial crack size distribution and the probability of having a crack. These two factors are currently sources of considerable uncertainty, and their absence from the relative benefit allows the influence of ISI to be assessed with greater confidence then if they were present in Eqn. (29). This result is for only one dimensional crack. The degree to which it is applicable to the more realistic case of two-dimensional cracks will be addressed in the following section.

\subsection{Probability of detection curves}

NDE techniques do not detect all cracks, but can be thought of as detecting cracks with a probability that depends on crack size. Detecting a crack depends on many factors, including the dominant degradation mechanism; the flaw location (e.g. surface or buried), orientation, and shape; material (e.g. stainless and ferritic steel); the inspector's training and experience; and the inspection method and procedure. In the literature, the POD has been used to define the capability of specific NDE techniques and inspection teams (Doctor et al., 1983), (Taylor et al., 1989) and (Heasler, 1996). Usually, however, the POD curve is given as a function of the defect size (depth) with all other factors governing detection assumed to be held constant for each given POD curve. In this paper, the POD curve is taken to be the measure of inspection reliability. 
In general, the POD curve for a certain NDE method, procedure, and inspection team is estimated based on a statistical methodology using the experimental data, expert elicitation, or both data and elicitation. The characteristic POD curves for detection of IGSCC discussed here are based on expert judgement. Alternative inspection strategies for ultrasonic examination of welds in stainless steel piping were evaluated based on a range of POD curves. The approach was to establish three POD curves that represented widely differing levels of NDE performance. These curves were intended to bound the performance expected from inspection teams operating in the field. To establish the POD curves, an informal expert judgement elicitation was made using staff at PNNL with knowledge of NDE performance data from inspection round robins and of recent industry efforts in the area of NDE performance demonstrations.

It was recognized that a population of inspection teams operating under field conditions can exhibit a considerable range of POD performance, even though all such teams have successfully completed a performance demonstration. The basic premise in estimating POD curves for the present calculations was that all teams had passed the ASME Section XI Appendix VIII performance demonstration. The informal expert judgement also considered information and trends observed in the PNNL round-robin studies on UT inspection (Doctor et al., 1983). The NDE experts at PNNL were asked to define POD curves by estimating parameters for the following form of a POD function:

$$
P_{N D}=\varepsilon+\frac{1}{2}(1-\varepsilon) \operatorname{erfC}\left[\nu \ln \left(\frac{A}{A^{*}}\right)\right]
$$

where $P_{N D}$ is the probability of nondetection, A is the area of the crack, $A^{*}$ is the area of crack for $50 \% P_{N D}, \varepsilon$ is the smallest possible $P_{N D}$ for very large cracks, and $v$ is the 'slope' of the PND curve. Based on measured performance for PNNL's mini round robin teams, a range of estimates for $\mathrm{A}^{*}$ (crack area for 50\% POD) was provided by the NDE experts. Harris et al. (Harris et al., 1981) assumed that the 'slope' parameter $v$ is 1.6. Several POD curves from PNNL studies were reviewed, and it was determined that a value of $v=1.6$ was consistent with published curves. The slope was correlated to the detection threshold parameter $A^{*}$ and the value of $\varepsilon$ was assigned to ensure that a smaller value of $A^{*}$ also implies a smaller value of $\varepsilon$. Three POD curves were selected:

1. Marginal performance: POD performance that is described by this curve would represent a team having only a small chance of passing an Appendix VIII performance demonstration.

2. Good performance: POD performance that is described by these curves corresponds to the better teams in the round robins.

3. Very good performance: this curve corresponds to a team that significantly exceeds the minimum level of performance needed to pass an Appendix VIII performance demonstration test.

Table 3 summarizes the input data for the above three POD curves. These particular curves assume that POD is a function of the crack depth as a fraction of pipe-wall thickness, 
independent of the actual wall thickness. Parameters indicated in Table 3 are considered appropriate to wall thicknesses of $25.4 \mathrm{~mm}$ and greater. Lower levels of POD as a function of a/h should be assumed for thinner-walled pipe. The parameter $\mathrm{a}^{*}$ is the crack depth for $50 \%$ probability of non-detection and is related to $A^{*}$ (i.e., $A^{*}=\pi / 4 D_{B} a^{*}$, where $D_{B}$ is the beam diameter of the ultrasonic probe). The parameter $a^{*}$ varies in the same manner as $\varepsilon$.

\begin{tabular}{|c|c|c|c|}
\hline Inspection Performance Level & $a^{*} / h^{(+)}$ & $\varepsilon$ & $v$ \\
\hline Marginal & 0.65 & 0.25 & 1.40 \\
\hline Good & 0.40 & 0.10 & 1.60 \\
\hline Very Good & 0.15 & 0.02 & 1.60 \\
\hline${ }^{(+)} h$ is the wall thickness of the pipe. & & & \\
\hline
\end{tabular}

Table 3. POD Curve parameters for three performance levels

\subsection{Factor of improvement}

The effectiveness of an inspection strategy is quantified by the parameter 'Factor of Improvement $(\mathrm{FI})^{\prime}$, which is the relative increase in piping reliability due to a given inspection strategy as compared with the strategy of performing no inspection. The results of a systematic set of calculations are presented in this paper that address inspection effectiveness for operating stresses giving crack growth rates ranging from very low to very high. Inspection strategies are described that address three reference levels of ultrasonic inspection reliability, intervals between inspections ranging from 1 to 10 years, and inservice inspections. The FI is based on the cumulative leak probability that occurs over the 40-year design life of the plant, and is defined as the ratio

$$
F I=\frac{\text { leak probability at } 40 \text { years without } N D E}{\text { leak probability at } 40 \text { years with } N D E}
$$

\section{Results}

\subsection{Predicted leak probability versus damage parameter}

The reliability for a large number of welds and fittings in a piping system can be estimated quickly if the results of detailed Monte Carlo simulations are provided in a structured parametric format. Dsigma Values for various degrees of sensitization, different levels of applied stress, a conductivity equal to $0.2 \mu \mathrm{S} / \mathrm{cm}$, different steady state temperature and different $\mathrm{O}_{2}$ content are presented in Fig.6(a-d). The parametric calculations as presented below consisted of many pc-PRAISE runs that covered a range of leak probabilities from 1.0E-04 to 1.0. It was believed that $D_{\text {sigma }}$ could serve as a suitable parameter to summarize results for calculated failure probabilities of stainless steel piping. Results presented later in this section show a good correlation between 40 -year cumulative leak probabilities and $D_{\text {sigma. }}$. Although the correlation tends to break down for smaller values of $D_{\text {sigma, }}$, the parameter does provide a useful basis to generalize results for piping-leak probabilities (Fig.7). 
(a)
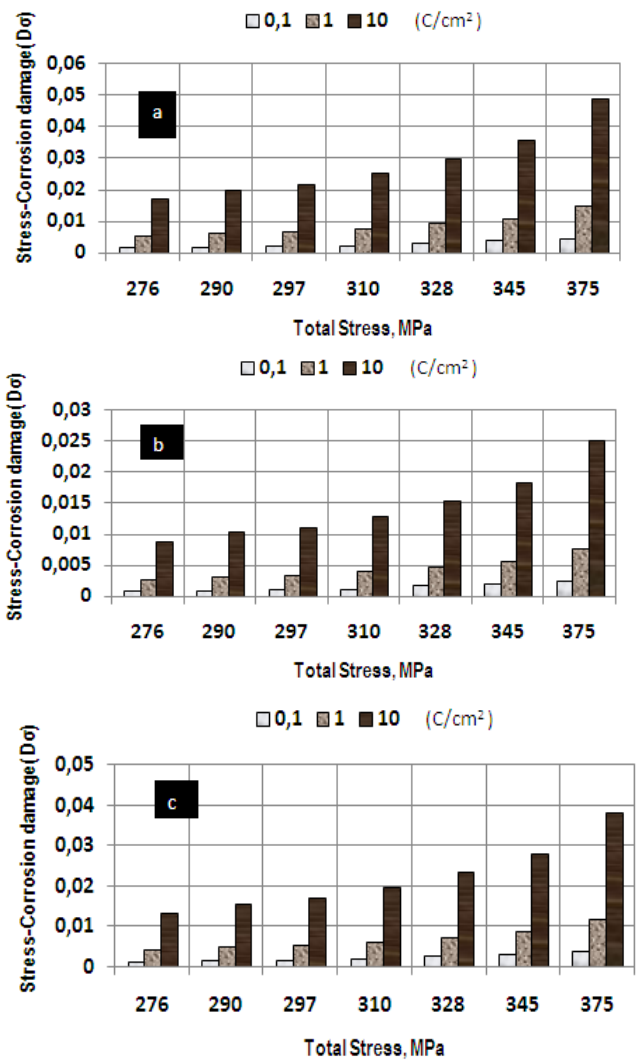

(d)

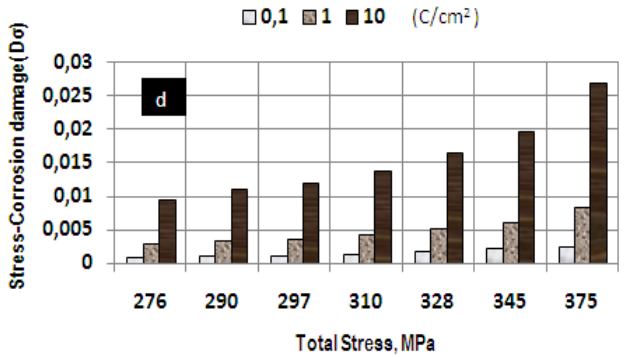

Figure 6. a: $D_{\text {sigma }}$ Values for various degrees of sensitization, different levels of applied stress, a conductivity equal to $0.2 \mu \mathrm{S} / \mathrm{cm}$ and a steady state temperature equal to $288^{\circ} \mathrm{C}$, for $\mathrm{O}_{2}$ content equal to $8 \mathrm{ppm}$. b: $D_{\text {sigma }}$ Values for various degrees of sensitization, different levels of applied stress, a conductivity equal to $0.2 \mu \mathrm{S} / \mathrm{cm}$ and a steady state temperature equal to $288^{\circ} \mathrm{C}$, for $\mathrm{O}_{2}$ content equal to $0.2 \mathrm{ppm}$. c: $D_{\text {sigma }}$ Values for various degrees of sensitization, different levels of applied stress, a conductivity equal to $0.2 \mu \mathrm{S} / \mathrm{cm}$ and a steady state temperature equal to $288^{\circ} \mathrm{C}$, for $\mathrm{O}_{2}$ content equal to $2 \mathrm{ppm}$. d: $D_{\text {sigma }}$ Values for various degrees of sensitization, different levels of applied stress, a conductivity equal to $0.2 \mu \mathrm{S} / \mathrm{cm}$ and a steady state temperature equal to $140^{\circ} \mathrm{C}$, for $\mathrm{O}_{2}$ content equal to $0.2 \mathrm{ppm}$. 


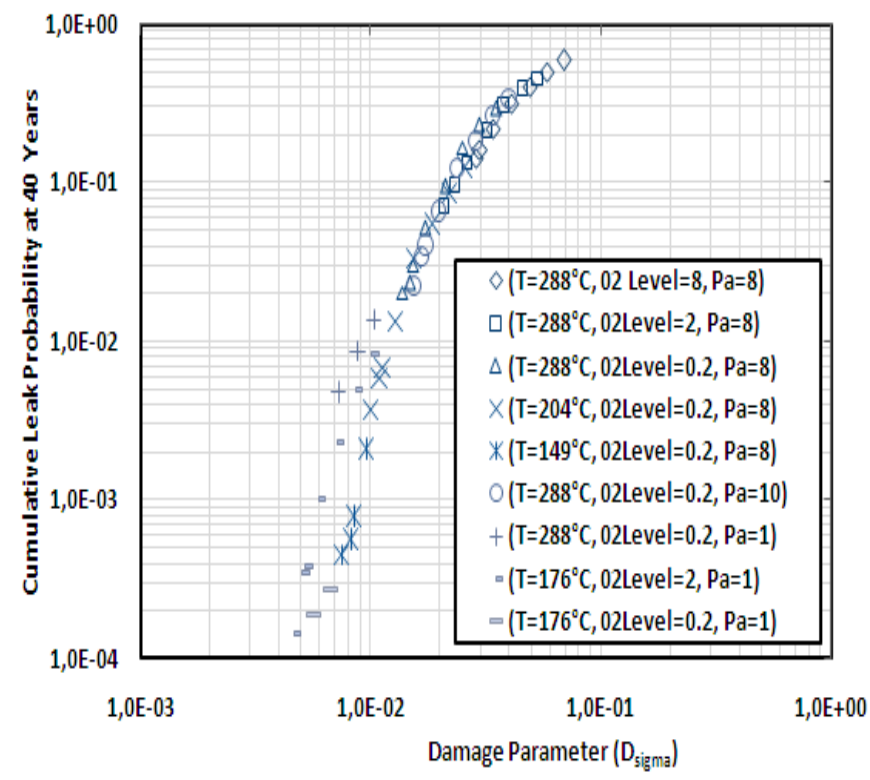

Figure 7. Cumulative Leak Probability over 40 Years as a Function of the Stress-Corrosion Damage Parameter for Various Temperatures, Oxygen Contents and degrees of sensitization

\subsection{Improvement factors}

The individual data points for improvement factors exhibited some data scatter, which was addressed by using a regression analysis to establish best fit curves (second order polynomial) in terms of improvement factors versus the logarithm (base 10) of $D_{\text {sigma }}$ and the corresponding leak probabilities. For clarity, the plots below show only the best-fit curves rather than the individual data points. Figs. (8-12) show calculated improvement factors (over a 40-year design life).

Figs. (8-10) each addresses a specific inspection method (POD curve) with the individual curves corresponding to different inspection intervals ranging from 1 to 10 years. Figs. (1012) have rearranged the curves to maintain a common inspection interval for each plot, with the individual curves corresponding to different POD capabilities. In general, it appears that a given inspection strategy (combination of POD curve and inspection interval) gives somewhat greater improvement factors. 


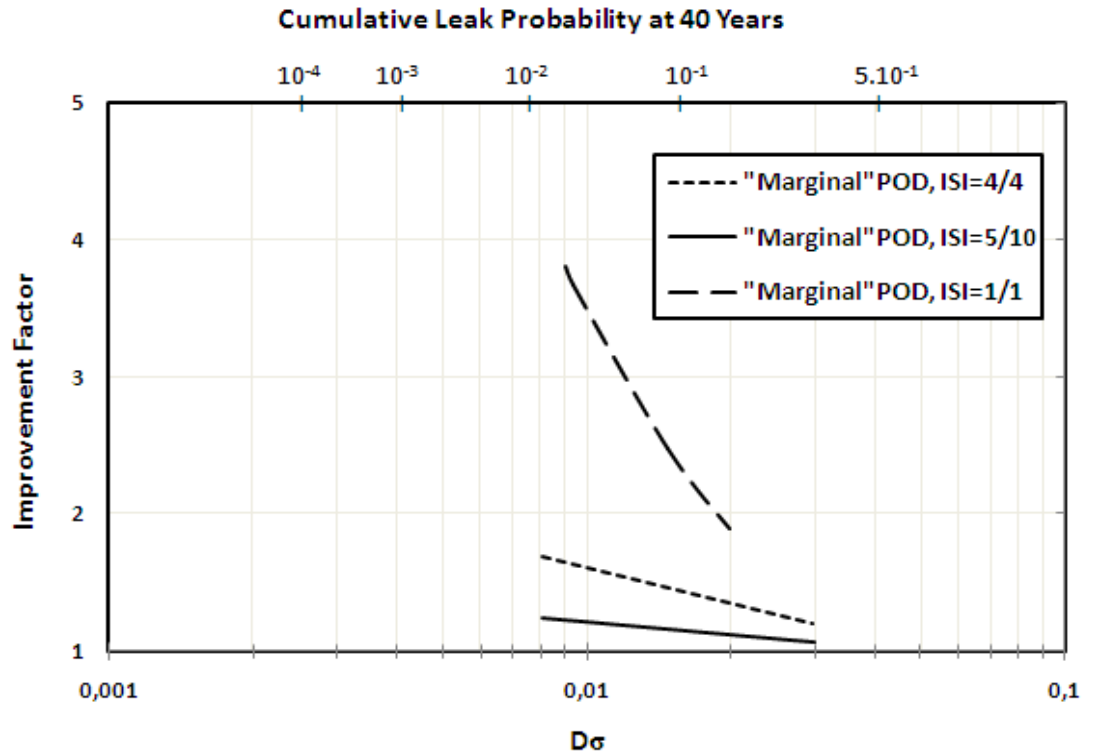

Figure 8. Improvement Factors versus $D_{\text {sigma }}$ for "Marginal" POD Curve with various Inspection Intervals

\section{Cumulative Leak Probability at $\mathbf{4 0}$ Years}

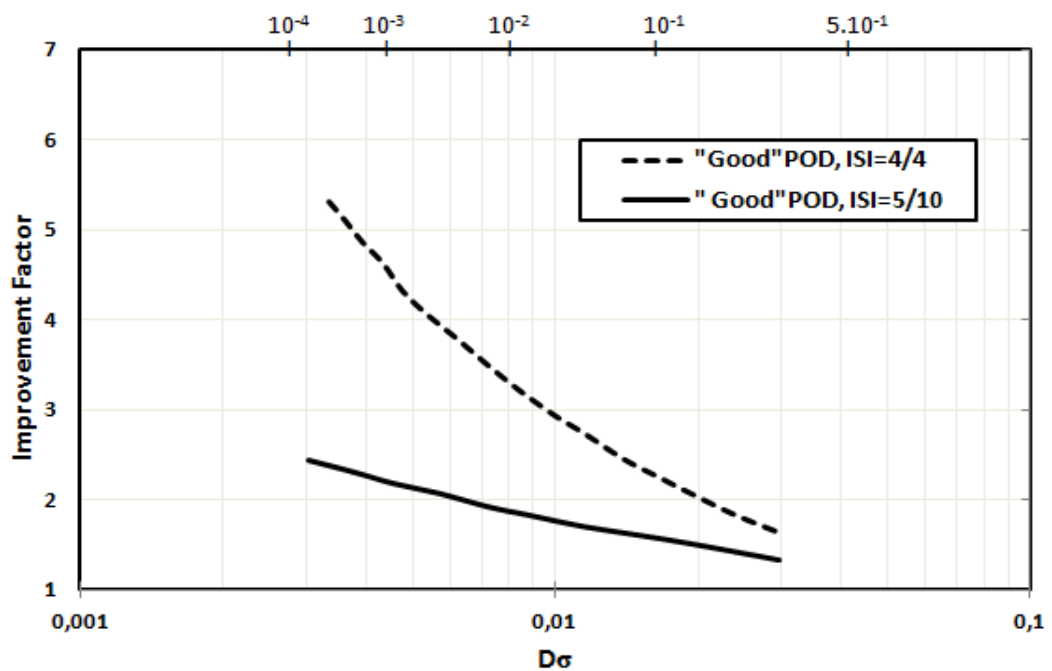

Figure 9. Improvement Factors versus $D_{\text {sigma }}$ for "Good" POD Curve with various Inspection Intervals 


\section{Cumulative Leak Probability at 40 Years}

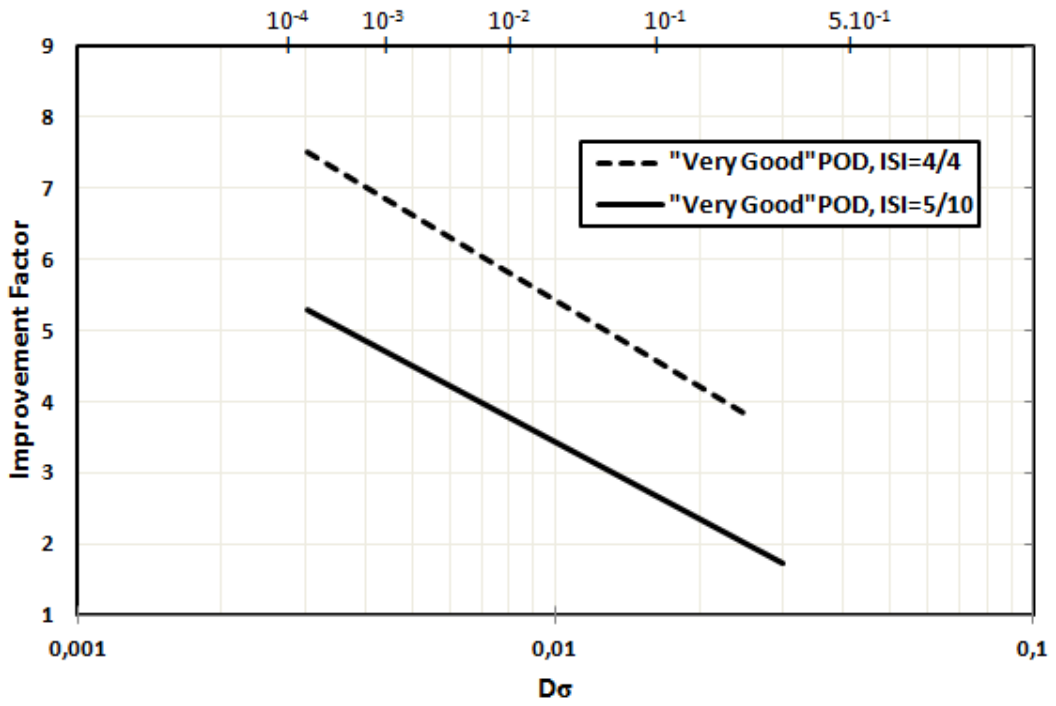

Figure 10. Improvement Factors versus $D_{\text {sigma }}$ for "Very Good" POD Curve with various Inspection Intervals

\section{Cumulative Leak Probability at 40 Years}

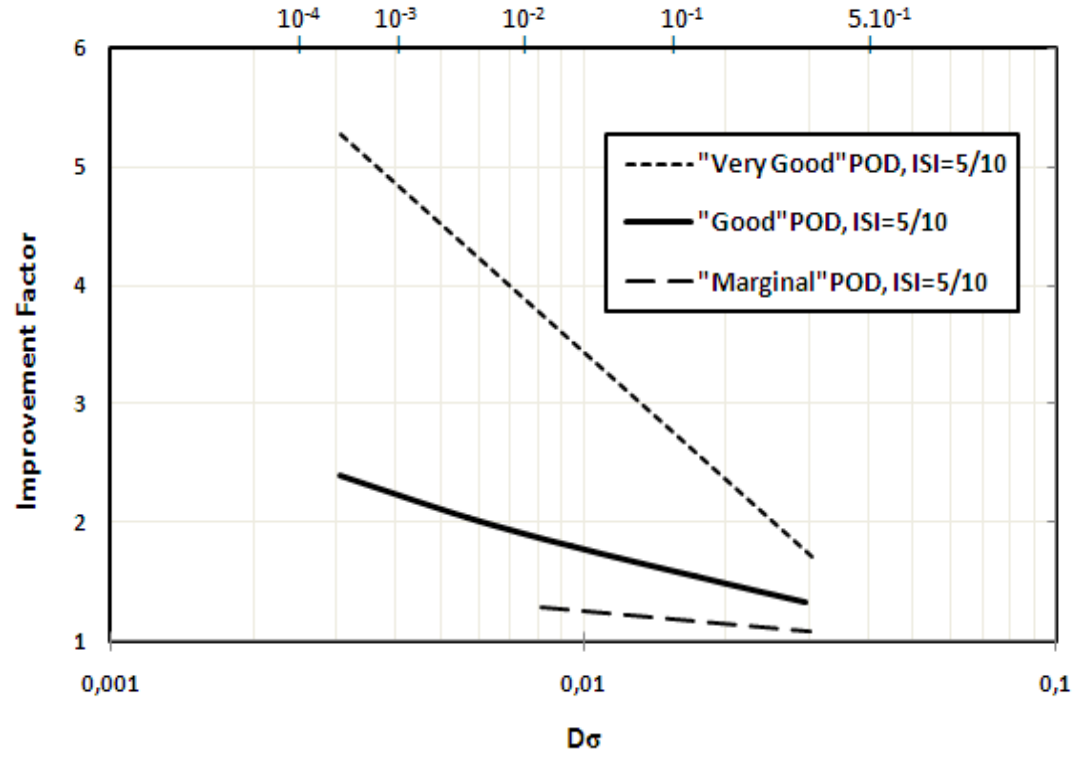

Figure 11. Improvement Factors versus $D_{\text {sigma }}$ for 10-Year ISI Interval with various POD Curves 


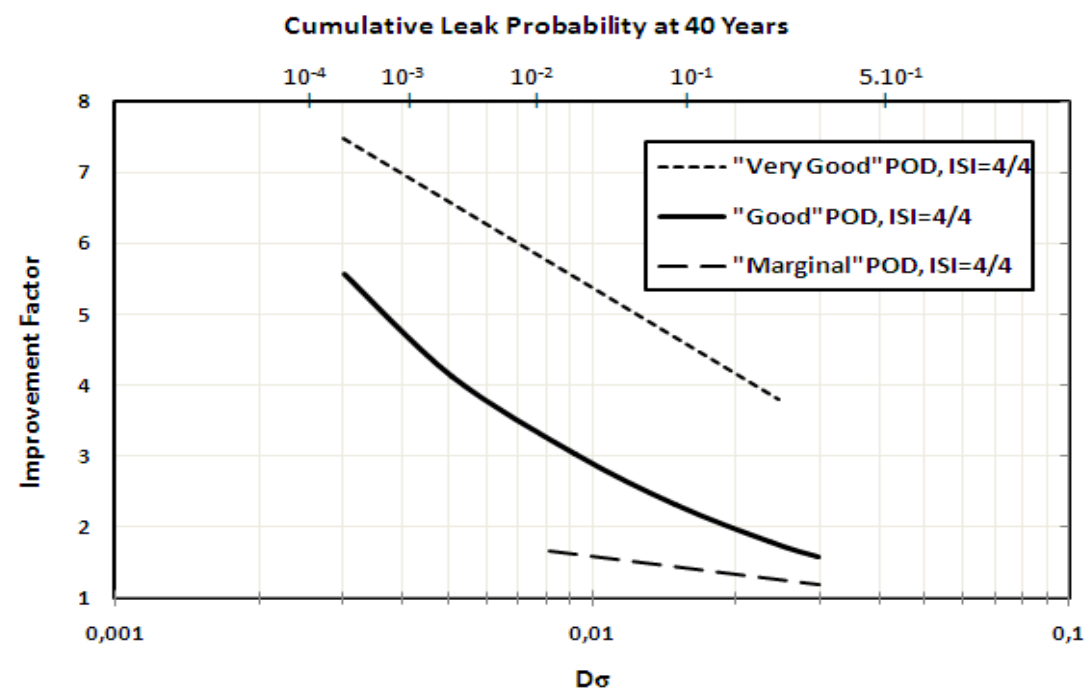

Figure 12. Improvement Factors versus $D_{\text {sigma }}$ for 4 -Year ISI Interval with various POD Curves

\section{Conclusions}

Stress corrosion crack growth can occur under constant loading conditions, and is therefore very different from crack growth driven by the cyclic loading. Our original probabilistic fracture mechanics model incorporated a simple model of stress corrosion cracking, based on the assumption that crack growth velocity in either the radial or circumferential direction is controlled by the value of stress intensity factor (for a given material and environment) at the crack tip. This model described crack kinetics by a simple functional relationship between crack growth rate and stress intensity factor. This probabilistic stress-corrosion cracking model was applied to assess the effect of various inspection scenarios on leak probabilities. This chapter has also discussed probability of detection curves and the benefits of in-service inspection in the framework of reductions in the leak probabilities for nuclear piping systems subjected to IGSCC. The results for typical NDE performance levels indicate that low inspection frequencies (e.g., one inspection every 10 years) can provide only modest reductions in failure probabilities. More frequent inspections appear to be even more effective. The greatest benefits are predicted for the "Very Good" NDE technology and procedures, for which an order-of-magnitude improvement on the leak probability can be achieved 
for an inspection frequency of once per year. The lower benefits of ISI for IGSCC compared to the benefits for fatigue crack growth can be explained in terms of long incubation periods for stress-corrosion cracking followed by a period of rapid crack growth.

\section{Author details}

A. Guedri

InfraRes Laboratory; University of Souk Ahras,

Algeria

LEM3 Laboratory, UMR CNRS 7239, University of Metz,

France

Y. Djebbar

InfraRes Laboratory; University of Souk Ahras,

Algeria

Moe. Khaleel

Pacific Northwest National Laboratory,

USA

A. Zeghloul

LEM3 Laboratory, UMR CNRS 7239, University of Metz,

France

\section{Acknowledgement}

The authors would like to thank Dr. Khaleel Mohammad for his support and his invaluable guidance during the course of this work.

\section{References}

A. Guedri, A. Zeghloul and B. Merzoug (2009) Reliability analysis of BWR piping including the effect of residual Stresses. International Review of Mechanical Engineering (I.RE.M.E.), pp.640-645, September 2009, Vol. 3, n. 5.

A. Guedri, B. Merzoug, Moe Khaleel and A. Zeghloul (2009) Reliability analysis of low alloy ferritic piping materials. Springer Netherlands, Damage and Fracture Mechanics. Failure Analysis of Engineering Materials and Structures, pp 33-42.

American Society of Materials (1996). ASM handbook: fatigue and fracture. USA: Materials Information Society International.

American Society of Mechanical Engineers (1998) ASME Boiler and Pressure Vessel Code, Materials, Section IIPart D: Properties, (ASME, New York). 
Andresen PL and FP Ford (1994) Fundamental Modeling of Environment Cracking for Improved Design and Lifetime Evaluation in BWRs." International Journal of Pressure Vessels and Piping 59(1-3): 61-70.

Anoop M B, Balaji Rao K, Lakshmanan N (2008) Safety assessment of austenitic steel nuclear power plant pipelines against stress corrosion cracking in the presence of hybrid uncertainties. International Journal of Pressure Vessels and Piping. 85(4): 238247

Bell CD and OJV Chapman (2003) Description of PRODIGAL. NURBIM Report D4/Appendix F. Rolls-Royce plc., Derby, United Kingdom.

Bishop BA. (1997) An Updated Structural Reliability Model for Piping Risk Informed ISI, In Fatigue and Fracture, Volume 2, PVP Vol. 346, pp. 245-252. American Society of Mechanical Engineers, New York.

Brickstad B and W Zang. (2001) NURBIT Nuclear RBI Analysis Tool, A Software for Risk Management of Nuclear Components. Technical Report No 10334900-1. DNV, Stockholm, Sweden.

Brickstad B, OJV Chapman, T Schimpfke, H Schulz and A Muhammed (2004) Review and Benchmarking of SRM and Associated Software. NURBIM Final Report D4, Contract FIKS-CT-2001-00172. DNV, Stockholm, Sweden.

Dillstrom P. (2003) A Short Description of ProSACC. NURBIM Report D4/Appendix G. DNV, Stockholm, Sweden.

Doctor SR, FL Becker, PG Heasler and GP Selby (1983) Effectiveness of U.S. Inservice Inspection Technologies: A Round Robin Test." In Proceedings of a Specialist Meeting on Defect Detection and Sizing, Vol. 2 (CSNI Report No. 75 and EUR 9066 II EN), pp. 669678.

General Electric Company. (1982a) The Growth and Stability of Stress Corrosion Cracks in Large Diameter BWR Piping, Volume 1: Summary. EPRI NP-2472, Vol. 1. BWR Owners Groups and Electric Power Research Institute, Palo Alto, California.

General Electric Company. (1982b) The Growth and Stability of Stress Corrosion Cracks in Large Diameter BWR Piping, Volume 2: Appendixes. EPRI NP-2472, Vol. 2. BWR Owners Groups and Electric Power Research Institute, Palo Alto, California.

Gosselin SR, FA Simonen, RG Carter, JM Davis and GL Stevens (2005) Enhanced ASME Section XI Appendix L Flaw Tolerance Procedure." In Proceedings of the PVP2005, 2005 ASME Pressure Vessels and Piping Conference, PVP2005-71100, July 17-21, 2005, Denver, Colorado. American Society of Mechanical Engineers, New York.

Harris DO and DD Dedhia (1998) WinPRAISE 98 PRAISE Code in Windows. Engineering Mechanics Technology, Inc., San Jose, California.

Harris DO, DD Dedhia and ED Eason (1986a) Probabilistic Analysis of Initiation and Growth of Stress Corrosion Cracks in BWR Piping." American Society of Mechanical Engineers, New York. ASME Paper 86-PVP-11. 
Harris DO, DD Dedhia and SC Lu. (1992) Theoretical and User's Manual for pcPRAISE, A Probabilistic Fracture Mechanics Computer Code for Piping Reliability Analysis. NUREG/CR-5864.U.S. Nuclear Regulatory Commission, Washington, D.C.

Harris DO, DD Dedhia, ED Eason and SD Patterson (1986b) Probability of Failure in BWR Reactor Coolant Piping: Probabilistic Treatment of Stress Corrosion Cracking in 304 and 316NG BWR Piping Weldments. NUREG/CR-4792, Vol. 3. U.S. Nuclear Regulatory Commission, Washington, D.C.

Harris DO, DD Dedhia, ED Eason, and SD Patterson (1985) Probabilistic Treatment of Stress Corrosion Cracking in Sensitized 304 Stainless Steel Weldments in BWR Piping. Failure Analysis Associates Report to Lawrence Livermore National Laboratory, Livermore, California.

Harris DO, EY Lim and DD Dedhia (1981) Probability of Pipe Fracture in the Primary Coolant Loop of a PWR Plant Volume 5: Probabilistic Fracture Mechanics Analysis Load Combination Program Project 1 Final Report. NUREG/CR-2189, Vol. 5. U.S. Nuclear Regulatory Commission, Washington, D.C.

Harris, D. O. and Lim, E. Y., (1983) Applications of a Probabilistic Fracture Mechanics Model to the Influence of In-Service Inspection on Structural Reliability, Probabilistic Fracture Mechanics and Fatigue Methods: Applications for Structural Design and Maintenance, ASTM STP 798, J. M. Bloom and J. C. Ekvall, Eds. , American Society for Testing and Materials, pp. 19-41.

Hazelton W and WH Koo. (1988) Technical Report on Material Selection and Processing Guidelines for BWR Coolant Pressure Boundary Piping. NUREG-0313, Rev. 2. U.S. Nuclear Regulatory Commission, Washington, D.C.

Heasler PG and SR Doctor. (1996) Piping Inspection Round Robin. NUREG/CR-5068, PNNL10475.U.S. Nuclear Regulatory Commission, Washington, D.C.

Helie M, Peyrat C, Raquet G, Santarini G, Sornay Ph (1996) Phenomenological modelling of stress corrosion cracking. Intercorr/96 First Global Internet Corrosion Conference.

Herrera ML, Mattson RA, Tang SS, Ahlgren CS. (1999) Probabilistic fracture mechanics analysis to justify in-service inspection intervals for the Helms penstock field welds. Proceedings of Waterpower '99-hydro's future: technology, markets and policy, Las Vegas, NV, July 6-9.

Khaleel MA and F Simonen. (1994a) The Effects of Initial Flaw Sizes and Inservice Inspection on Piping Reliability." In Service Experience and Reliability Improvement: Nuclear, Fossil, and Petrochemical Plants, PVP-Vol. 288, pp. 95-07. American Society of Mechanical Engineers, New York.

Khaleel MA and FA Simonen (1994b) A Parametric Approach to Predicting the Effects of Fatigue on Piping Reliability. In Service Experience and Reliability Improvement: Nuclear, Fossil, and Petrochemical Plants, PVP-Vol. 288, pp. 117-125. American Society of Mechanical Engineers, New York. 
Khaleel MA and FA Simonen (2000) Effects of Alternative Inspection Strategies on Piping Reliability. Nuclear Engineering and Design 197:115-140.

Khaleel MA, FA Simonen, DO Harris, and D Dedhia (1995) The Impact of Inspection on Intergranular Stress Corrosion Cracking for Stainless Steel Piping." In Risk and Safety Assessments: Where Is the Balance? PVP-Vol. 296, pp. 411- 422. American Society of Mechanical Engineers, New York.

Khaleel MA, FA Simonen, HK Phan, DO Harris and D Dedhia (2000) Fatigue Analysis of Components for 60-Year Plant Life. NUREG/CR-6674, PNNL-13227. U.S. Nuclear Regulatory Commission, Washington, DC.

Lu B T, Chen Z T, Luo J L, Patchett B M, Xu Z H (2005) Pitting and stress corrosion cracking behaviour in welded austenitic stainless steel. Electrochimica Acta 50(6): 13911403

Mohammed AA. (2003) A Short Description of STRUEL. NURBIM Report D4/Appendix H. The Welding Institute, Cambridge, United Kingdom.

Priya C, Balaji Rao K, Lakshmanan N, Gopika V, Kushwaha H S, Saraf R K (2005) Probabilistic failure analysis of austenitic nuclear pipelines against stress corrosion cracking. Proc. Inst. Mech. Eng. Part C: J. Mech. Eng. Sci. 219(7): 607-626

Rahman S. (1997) A computer model for probabilistic leak-rate analysis of nuclear piping and piping welds. International Journal of Pressure Vessels and Piping; 70:209_ 21.

Schimpfke T. (2003) A Short Description of the Piping Reliability Code PROST. NURBIM Report D4/Appendix C. Gesellschaft fur Anlagen-und Reaktorsicherheit (GRS), Berlin, Germany.

Simonen FA and MA Khaleel (1998a) A Probabilistic Fracture Mechanics Model for Fatigue Crack Initiation in Piping." In Fatigue, Fracture and Residual Stress, PVP-Vol. 373, pp. 27-34. American Society of Mechanical Engineers, New York.

Simonen FA and MA Khaleel (1998b) Effects of Flaw Sizing Errors on the Reliability of Vessels and Piping." ASME Journal of Pressure Vessel Technology 120:365373.

Simonen FA, DO Harris and DD Dedhia (1998) Effect of Leak Detection on Piping Failure Probabilities." In Fatigue Fracture and Residual Stress, PVP-Vol. 373, pp. 105-113. American Society of Mechanical Engineers, New York.

Taylor TT, JC Spanner, PG Heasler, SR Doctor and JD Deffenbaugh (1989) An Evaluation of Human Reliability in Ultrasonic Inservice Inspection for Intergranular Stress Corrosion Cracking Through Round Robin Testing." Mater Eval 47:338.

Ting K. (1999) The evaluation of intergranular stress corrosion cracking problems of stainless steel piping in Taiwan BWR-6 nuclear power plant. Nucl. Eng. Design; 191(2): 245-54.

You J-S, Wu W-F. (2002) Probabilistic failure analysis of nuclear piping with empirical study of Taiwan's BWR plants. International Journal of Pressure Vessels and Piping. 79(7):483-92. 
Zhang S, Shibata T, Haruna T. (1997) Initiation and propagation of IGSCC for s ensitized type 304 stainless steel in dilute sulfate solutions. Corrosion Science; 39(9):172539. 